\title{
Effect of the Asn side chain on the dissociation of deprotonated peptides elucidated by IRMPD spectroscopy
}

Josipa Grzetic ${ }^{\mathrm{a}}$ and Jos Oomens $\mathrm{s}^{\mathrm{a}, \mathrm{b}}$ *

${ }^{a}$ Radboud University Nijmegen, Institute for Molecules and Materials, FELIX Facility, Toernooiveld 7, 6525ED Nijmegen, The Netherlands

${ }^{b}$ Van 't Hoff Institute for Molecular Sciences, University of Amsterdam, Science Park 904, 1098XH Amsterdam, The Netherlands

* Corresponding author: joso@science.ru.nl / +31 243652422 / +31 243652410

Keywords: Deprotonated peptide; asparagine; peptide fragmentation; ion spectroscopy; succinimide

Dedication: This paper is dedicated to the memory of our dear friend Detlef Schröder. 


\section{Table of contents graphic}

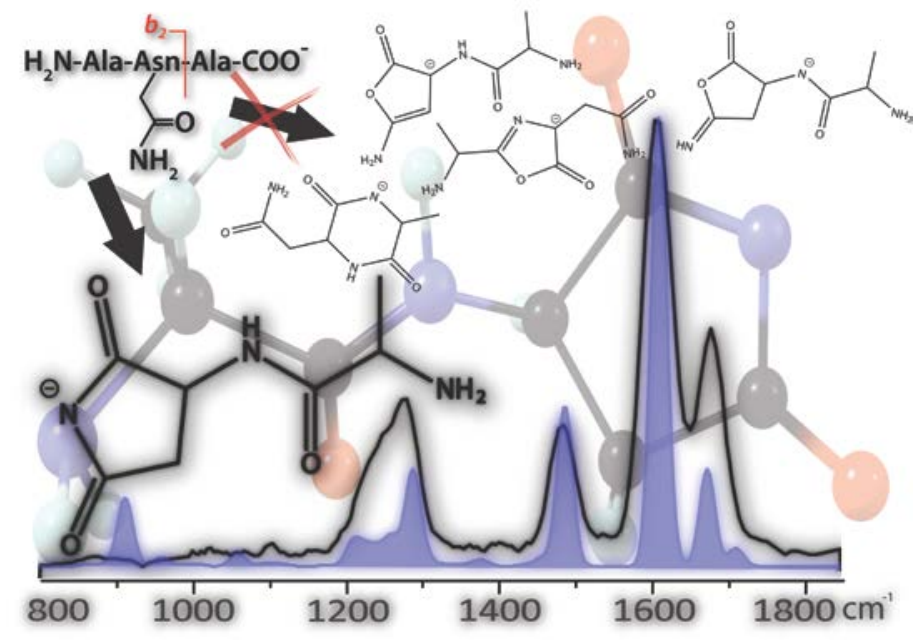

\section{Highlights}

- Non-oxazolone $b$-type fragments identified for deprotonated peptides

- $\quad b$-type anions from Asn-containing peptides have succinimide structure

- $b_{2}$ and $b_{3}$ anions investigated

- IR spectroscopy distinguishes between imide and isoimide structures 


\begin{abstract}
Infrared ion spectroscopy using the free electron laser FELIX was applied to identify the structure of $b$-type peptide fragments generated by collision and IR multiple-photon induced dissociation from singly deprotonated peptides containing an asparagine residue, in particular AlaAsnAla (ANA) and AlaAlaAsnAla (AANA). IR spectra were recorded over the $800-1800 \mathrm{~cm}^{-1}$ spectral range by multiple-photon dissociation (IRMPD) spectroscopy and have been compared with density functional theory (DFT) calculated spectra at the B3LYP/6-31++G(d,p) level for different isomeric ion structures for structural characterization. Results unambiguously show that the $b_{2}$ and $b_{3}$ fragment anions do not possess the common oxazolone or diketopiperazine structure, but involve cyclization of the asparagine side chain. Nucleophilic attack from the side chain amide nitrogen on the peptide backbone carbonyl carbon leads to the formation of cyclic succinimide structures. Deprotonation is shown to occur on the succinimide nitrogen, which delocalizes the negative charge over two adjacent carbonyl groups thus enhancing the gasphase stability.
\end{abstract}




\section{Introduction}

Sequencing of proteolytic peptides using mass spectrometry techniques is one of the main tools in proteomics research[1-3]. It is essentially used to identify amino acid sequences of peptides. The practical use is based on the empirical differences in the $\mathrm{m} / \mathrm{z}$ values of peptide fragments created by collision-, photon- or electron-induced dissociation of protonated peptides. While this method of analyzing protein structures is widely accepted, the fundamental chemical reactions underlying peptide dissociation processes are only partially understood [4]. Using chemical intuition and the results of tandem MS experiments alone, various peptide fragment structures and corresponding dissociation pathways have been suggested in the literature. However, further computational and experimental evidence is usually required to firmly establish the suggested reaction pathways and product structures, especially since various isomeric and tautomeric structures are often conceivable. In addition to information based purely on quantum-chemical calculations, experimental evidence for fragment structures has recently been provided via a combination of MS instrumentation and tunable infrared lasers, which allows one to record IR spectra of the peptide fragment ions of interest [5-7]. Combining these experimental IR spectra with results of computational chemistry (or with experimental spectra of model compounds) the structure of peptide fragment ions can often be identified with high confidence. [8, 9].

Spectroscopic studies of collision induced dissociation (CID) products of protonated peptides have mainly focused on $a$ - and $b$-type fragments (peptide fragment nomenclature adopted from Roepstorff [10]) . It has been shown that depending on the amino acid sequence, $b_{2}$-type fragments can possess oxazolone or diketopiperazine structures [11-13]. Very recently we have also identified residue specific fragmentation of protonated peptides containing glutamine or asparagine residues (submitted). In contrast to formation of oxazolone and diketopiperazine $b_{2^{-}}$ type structures, here we noticed the interference of Asn and GIn residues in $b$-type ion formation; dissociation occurs via nucleophilic attack of the side chain amide nitrogen atom of Asn and GIn on the adjacent peptide carbonyl carbon, which leads to formation of succinimide and glutarimide ring structures for these $b$-type ions, respectively. In addition to the fragment 
structures above, ion spectroscopy was also instrumental in the discovery that larger $b$-ions can undergo "head-to-tail" cyclization leading to macrocyclic structures, which may reopen generating fragments with a permuted sequence [14-18]. Formation of macrocyclic structures was also reported for $a$-type peptide fragments [19, 20].

While MS-based peptide sequencing in proteomics research is almost exclusively based on fragmentation of protonated peptides, analyzing the fragmentation of deprotonated peptides may generate different fragmentation patterns and thus increase sequence coverage [21-24]. Moreover, for peptides containing many acidic residues or for phosphorylated peptides, running in negative ion mode, i.e., sequencing the deprotonated peptide, may be more efficient [25]. While fragmentation of protonated peptides mainly generates $a-, b$ - and $y$-type backbone fragments, peptide anion fragmentation features in addition $c$ - and $z$-type ions, which may also provide additional sequence information. Various studies have therefore addressed the mechanisms of fragmentation of deprotonated peptides using tandem MS and computational methods [22, 24, 26-34]. More recently, IR spectroscopy has been applied to elucidate the structure of anionic $a$-, $b$ - and $c$-type fragments; for the $a_{3}$ anion generated from deprotonated $\mathrm{Ala}_{3}$ a linear amidate structure was established [35]. The $b_{2}$-fragments generated from deprotonated AlaTyrAla and $\mathrm{Ala}_{3}$ adopt oxazolone structures deprotonated at the oxazolone carbon atom adjacent to the carbonyl carbon [36]. c-Type anions were spectroscopically shown to possess linear structures, where the deprotonation site is either the peptide bond nitrogen atom or the side chain for residues with relatively high gas-phase acidity [37].

As established for protonated peptides, the side chain of Asn and GIn may become involved in the rearrangement reactions forming $b_{2}$-type fragments [38-42]. It is therefore of interest to investigate what the effect of these residues is in the dissociation of deprotonated peptides. Glutamine and asparagine are amino acids which feature an amide group, which acts as a relatively strong nucleophile. Furthermore, they have been addressed as uniquely unstable residues under physiological conditions (i.e. in aqueous solution), spontaneously undergoing protein deamidation, where the amide group of Asn or Gln is converted to a carboxylate moiety. Structural changes of the protein upon such reactions induce biological responses such 
as molecular clocks for the timing of biological processes or acceleration of amyloid aggregate formation (pathological protein formation) $[43,44]$.

Here we present an IRMPD spectroscopic study on $b$-type peptide fragments generated from deprotonated peptides containing Asn, in particular for the $b_{2}$ anion from AlaAsnAla and the $b_{3}$ anion from AlaAlaAsnAla. A structural assignment is proposed based upon comparison of the experimental spectra with theoretically generated IR spectra for various isomeric candidate fragment structures.

\section{Experimental and computational methods}

\subsection{IRMPD Spectroscopy}

Infrared spectra were obtained by infrared multiple-photon dissociation (IRMPD) spectroscopy using the Fourier transform ion cyclotron resonance (FTICR) mass spectrometer coupled to the beam-line of the infrared free-electron laser FELIX $[7,45,46]$.

Deprotonated peptides were generated by electrospray ionization (ESI, Micromass Z-spray source) from approximately $0.5 \mathrm{mmol}$ solutions of the sample peptide in a 1:1 acetonitrile/water mixture with a drop of $10 \mathrm{mmol}$ ammonium hydroxide added to enhance the deprotonation. Solutions were always freshly made in order to avoid possible chemical modifications of the samples. Peptides (AlaAsnAla and AlaAlaAsnAla) were purchased from Genecust (Luxemburg) and used without further purification. The $b_{2}$ fragment from deprotonated ANA was generated by collision induced dissociation (CID) in the high-pressure region at the inlet of the mass spectrometer. The $b_{3}$ anion from AANA was generated in the FTICR cell by $0.1 \mathrm{~s}$ long $\mathrm{CO}_{2}$ laser (Universal laser systems, Scottsdale, USA, ULR-25) irradiation. The choice between these two methods of fragmentation was based on their efficiency in generating a high ion signal on the fragment ion of interest. For systems where both methods 
were used, we found no evidence of their IR spectra being different, suggesting that the same structure is generated independent of the fragmentation method used.

Inside the ICR cell, the ion of interest was isolated using a stored waveform inverse Fourier transform (SWIFT) excitation pulse[47]. While stored inside the ICR cell, the mass-selected fragment ion was irradiated with the IR beam from FELIX. FELIX produces $5 \mu$ s long pulses with an output pulse energy (at the ICR cell) of about $30-40 \mathrm{~mJ}$, while the bandwidth is about $0.5 \%$ of the central wavelength. The scanning range in these experiments was approximately 800-1900 $\mathrm{cm}^{-1}$. Ions were irradiated for $2.5 \mathrm{~s}$ while the entire FTICR sequence was $4.5 \mathrm{~s}$ long.

IRMPD spectroscopy is based on the assumption that only photons resonant with a vibrational band of the molecular ion are absorbed. The energy of the absorbed photon is randomized over all internal degrees of freedom by intramolecular vibrational distribution (IVR) on a sub-ps timescale. Thus, tens to hundreds of photons can be absorbed during a single FEL pulse raising the internal energy of the ion until it undergoes unimolecular dissociation. (See Ref. [48] for an interesting recent discussion by Detlef and his coworkers on the effects of IVR in IRMPD spectroscopy and possible breakdown of the assumption of ergodicity). After irradiation, a mass spectrum is generated using an excite/detect sequence as implemented in the FTICR software [49]. Three mass spectra are collected at each wavelength point and averaged. An IR spectrum is then generated by plotting the fragment ion yield as a function of wavelength, where the yield is calculated as $\Sigma I($ fragments) $/ \Sigma I($ all ions). The yield is linearly corrected for the laser power profile over the scan range.

\subsection{Density functional theory calculations}

DFT calculations were performed using the B3LYP functional with the $6-31++G(d, p)$ basis set implemented in Gaussian09 [50]. This method was found to give satisfactory results in previous experiments considering deprotonated species [51, 52]. Candidate input structures for these calculations are based on chemical intuition, where the number of hydrogen bonds was maximized and cis configurations of peptide bonds as well as eclipsed steric interactions were avoided. Computed harmonic vibrational frequencies were scaled by 0.975 and convoluted with 
a $25 \mathrm{~cm}^{-1}$ fwhm Gaussian line shape function to facilitate easy comparison with experimental spectra.

\section{Results and discussion}

\section{$3.1 \mathrm{~b}_{2}$ anion from AlaAsnAla}

As for protonated peptides, amide bond cleavage is a common peptide fragmentation pattern for deprotonated peptides, leading to the formation of $b$ - and $y$-type ions. Formation of $b$-type fragments from deprotonated peptides was first reported by Heerma and co-workers [53]. Two different $\mathrm{b}_{2}$-fragment ion structures were proposed: a linear amidate $b$-ion with a $\mathrm{C}=\mathrm{C}=\mathrm{O}$ unit at the C-terminus [54-56] and a deprotonated oxazolone structure $[33,57]$. The $b_{2}$ fragments generated from deprotonated $\mathrm{Ala}_{3}$ and deprotonated AlaTyrAla have been spectroscopically identified as oxazolones, as had indeed been suggested by Harrison et al.[33].

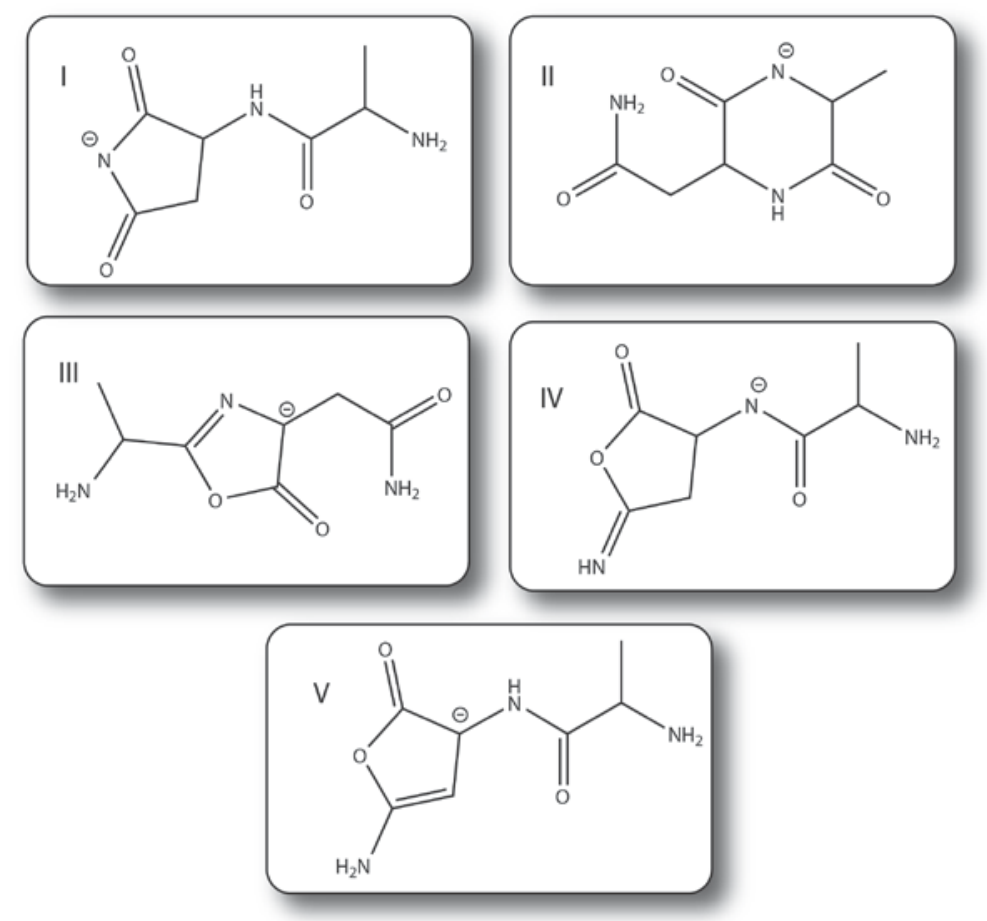

Figure 1. Suggested structures and deprotonation sites for $b_{2}$ peptide fragments generated from deprotonated ANA: succinimide structure deprotonated at succinimide nitrogen (I), diketopiperazine structure deprotonated at diketopiperazine ring nitrogen (II), oxazolone deprotonated at $\alpha$-carbon embedded in oxazolone ring (III), imino- $\gamma$-butyrolactone structure deprotonated at the peptide bond nitrogen (IV) and amino- $\gamma$-butyrolactone deprotonated at the $\alpha$-carbon in the butyrolactone ring. 
Apart from an oxazolone structure, conceivable structures for the $b_{2}$-ion of deprotonated AlaAsnAla are diketopiperazine, imino- $\gamma$-butyrolactone and succinimide as shown in Figure 1. While the oxazolone and diketopiperazine structures can be formed through nucleophilic attack by backbone $\mathrm{O}$ - and $\mathrm{N}$-atoms, the imino- $\gamma$-butyrolactone and succinimide structures are formed through nucleophilic attack by the Asn side chain $\mathrm{O}$ - and $\mathrm{N}$-atoms, respectively. For protonated peptides containing Asn, these alternative b-ion structures have been suggested [38] and the succinimide has indeed been spectroscopically identified very recently (submitted).
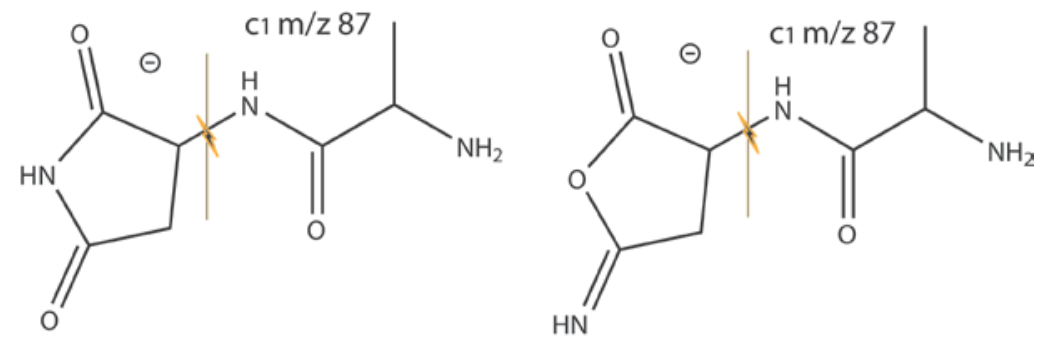

Figure 2. Succinimide or $\gamma$-butyrolactone? Observed IRMPD fragment ions ( $c_{1}$ ion and $\mathrm{m} / \mathrm{z}$ 96) of the $b_{2}$ anion can be explained by Asn side-chain involvement in the dissociation reaction of deprotonated ANA. However, the tandem MS data cannot distinguish between the presented structures - succinimide or imino- $\gamma$-butyrolactone.

Upon CID, deprotonated AlaAsnAla was found to dissociate mainly into the $b_{2}$ ion at $\mathrm{m} / \mathrm{z} 184$, with a minor $\mathrm{y}_{1}$ fragment at $\mathrm{m} / \mathrm{z} 88$. Upon IRMPD, the isolated $\mathrm{b}_{2}$ anion dissociates into $\mathrm{m} / \mathrm{z} 96$, $\mathrm{m} / \mathrm{z} 113$ and $\mathrm{m} / \mathrm{z} 87$ (in order of their abundance), corresponding to $\mathrm{C}_{4} \mathrm{H}_{2} \mathrm{NO}$ (maleimide anion, as will be shown below), deprotonated 5-amino-succinimide and the $c_{1}$ fragment, respectively. This fragmentation pattern is unlike that observed for oxazolone $b_{2}$-ions (Figure 1 , structure III) of deprotonated $\mathrm{Ala}_{3}$ and AlaTyrAla, for which the main neutral loss channels are $\mathrm{H}_{2} \mathrm{CO}, \mathrm{CO}_{2}$ and CO $[36,57]$. Moreover, the fragmentation pattern observed here is clearly different from the dissociation pathways of deprotonated diketopiperazines (Figure 1, structure II) [58]. Analyzing only this MS/MS part of the experimental data suggests that the fragments generated by IRMPD of the ANA $b_{2}$ anion are consistent with structures where the first peptide bond as well as the second $\mathrm{N}-\mathrm{C}_{\alpha}$ bond do not belong to any cyclic moieties, such as for structures I, IV and V in Figure 1. However, based on this data alone both succinimide and butyrolactone structures 
remain possible, since both of these structures match the hypothetical MS "puzzle" as depicted in Figure 2.

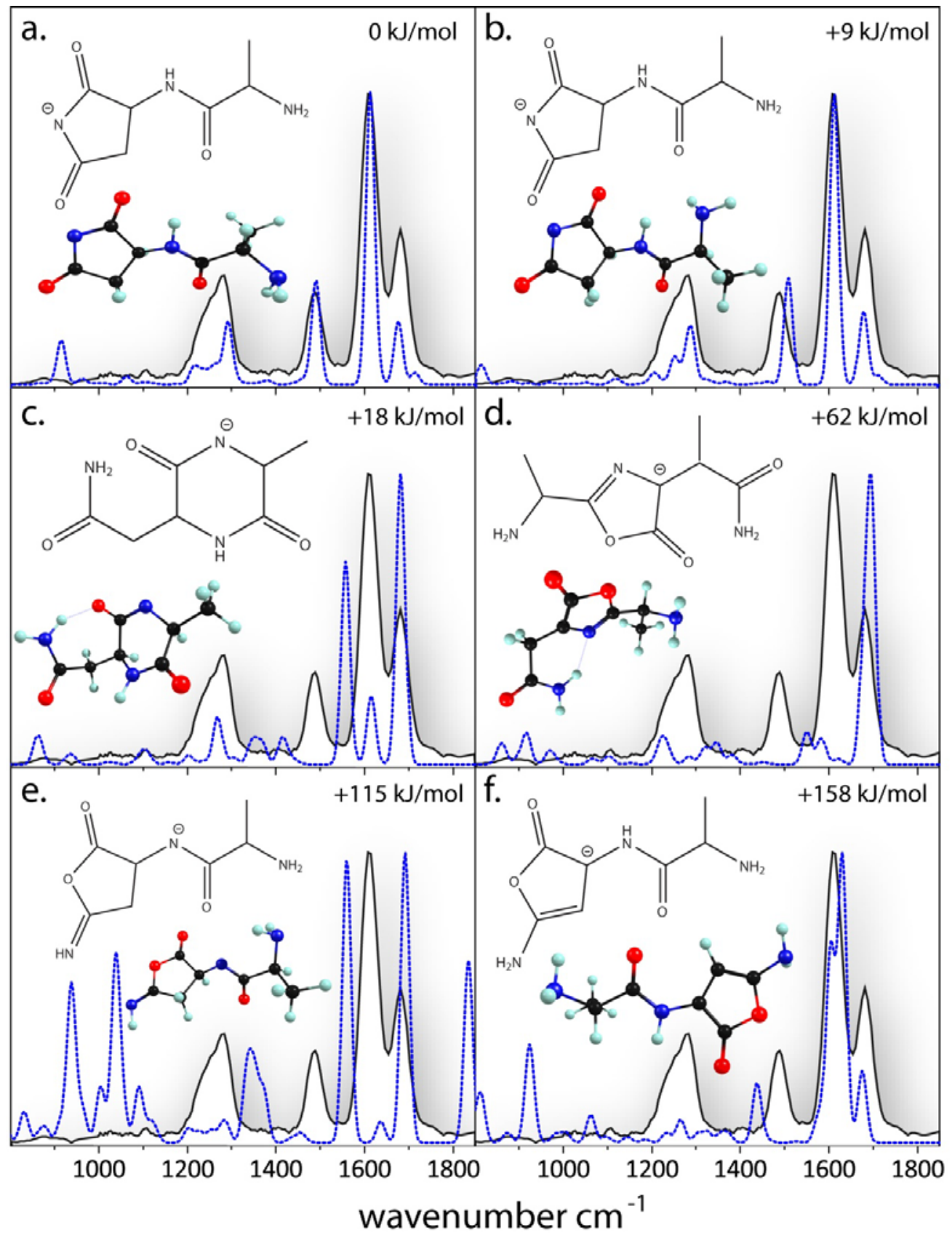

Figure 3. IRMPD spectrum of the $b_{2}$ ion of deprotonated ANA (black in all panels) compared to DFTcalculated spectra (blue dashed line) for candidate structures. Calculated relative free energies are given for each of the structures. 
In Figure 3, the experimental IRMPD spectrum of the $\mathrm{m} / \mathrm{z} 184$ anion is compared with calculated vibrational spectra for selected candidate structures: succinimide deprotonated at the succinimide nitrogen atom (Figure $3 a$ and $3 b$, showing two different conformations of structure I), diketopiperazine deprotonated at the diketopiperazine nitrogen atom (Figure 3c, structure II), oxazolone deprotonated at the $\alpha$-carbon atom in the oxazolone ring (Figure $3 d$, structure III), imino- $\gamma$-butyrolactone deprotonated at the peptide bond nitrogen atom (Figure $3 e$, structure IV) and amino- $\gamma$-butyrolactone deprotonated at the $\alpha$-carbon atom in the butyrolactone ring (Figure 3f, structure V). Relative free energy values are given for each of the structures in Figure 3. Other possible deprotonation sites for each of the presented isomeric structures were also investigated, but resulted in calculated spectra that clearly did not match with the experiment and that were much higher in relative free energy; these structures are therefore not presented.

Inspection of the six calculated spectra clearly suggests that only the succinimide conformers in panels $\mathrm{a}$ and $\mathrm{b}$ are in reasonable agreement with the experiment. The two conformers mainly differ in the orientation of the N-terminal amino-group with respect to the rest of the system, changing the $\mathrm{H}$-bonding of the $\mathrm{N}$-terminus. These succinimide structures have the lowest free energies of all isomers and their free energy difference is only $9 \mathrm{~kJ} / \mathrm{mol}$. Their calculated spectra are rather similar. Here, we analyze the observed bands based on the calculated vibrational spectrum of the lowest energy structure presented in panel a. The bands at 1715, 1676 and $1613 \mathrm{~cm}^{-1}$ in the computed spectrum correspond to the shoulder at $1730 \mathrm{~cm}^{-1}$ and the bands at 1680 and $1613 \mathrm{~cm}^{-1}$ in the experimental spectrum and are due to different carbonyl stretching modes: the symmetric carbonyl stretching mode of the succinimide ring, the peptide bond carbonyl stretch and the asymmetric stretching of the succinimide carbonyls, respectively. The band with relatively high intensity at $1491 \mathrm{~cm}^{-1}\left(1488 \mathrm{~cm}^{-1}\right.$ in the experiment) is assigned to the peptide bond $\mathrm{NH}$ wagging with some stretching contribution of the adjacent $\mathrm{N}-\mathrm{C}$ bond. For the conformer presented in panel a, this NH is hydrogen-bonded only with the succinimide oxygen atom. For the succinimide conformer shown in Figure $3 b$, this $\mathrm{NH}$ is in addition hydrogenbonded to the $\mathrm{N}$-terminal nitrogen atom, which results in a shift of the calculated $\mathrm{NH}$ wagging frequency to $1509 \mathrm{~cm}^{-1}$, making the match between experiment and theory slightly worse for 
conformer $b$. In the $1200-1300 \mathrm{~cm}^{-1}$ region, the most prominent band is at $1290 \mathrm{~cm}^{-1}\left(1283 \mathrm{~cm}^{-1}\right.$ in the experiment) and is due to succinimide NC stretching. Further small features that appear below $1290 \mathrm{~cm}^{-1}$ are due to different $\mathrm{C}-\mathrm{H}$ vibrations coupled to $\mathrm{N}-\mathrm{H}$ vibrations and they form a broad shoulder around $1230 \mathrm{~cm}^{-1}$. In the computed spectrum, one band appears that does not match our experimental data at $913 \mathrm{~cm}^{-1}$. This band is attributed to the $\mathrm{NH}_{2}$ bending mode, which is often a vibration with high anharmonic behavior $[59,60]$. Hence, we conclude that the agreement between theory and experiment is excellent for the lowest energy conformer in Figure 3a, particularly in the critically diagnostic spectral region above $1400 \mathrm{~cm}^{-1}$. However, considering the small relative energy difference and the spectral similarity, admixture of the conformer in Figure $3 b$ cannot be excluded. The $b_{2}$-ion of deprotonated ANA can thus safely be concluded to possess a succinimide structure deprotonated on the succinimide nitrogen atom.

\subsection{Proposed mechanism for $b_{2}$-ion formation}

A succinimide structure was previously proposed by Bowie and co-workers for the anion formed by water loss from deprotonated ValAsn [34]. Succinimide formation was also suggested for non-enzymatic deamidation in Asn-containing proteins and peptides in solution [61]. Based on these previous studies, a proposed mechanism for the formation of the succinimide $b_{2}$ anion is depicted in Scheme 1 . The site of initial deprotonation is taken to be the C-terminus, since the C-terminal proton is most acidic in the parent molecule $[62,63]$. Support for this assumption is further provided by the spectroscopic observation that the deprotonation site of $\mathrm{Ala}_{3}$ and AlaTyrAla, the latter containing a moderately acidic Tyr residue, is the Cterminus[35, 36].

The first step is proton transfer to the C-terminal carboxylate (see Scheme 1 ) and the question is which proton is mobilized. In peptides without acidic residues (Glu, Asp, Tyr), the next most acidic proton is an amide bond proton. In previous spectroscopic experiments on anionic $\mathrm{N}$ terminal a- and c-type peptide fragments, deprotonation at the peptide bond nitrogen has indeed been clearly identified[35, 37]. For peptides containing Asn or GIn residues with an 
amide moiety in their side chain, one may wonder whether the side chain amide is more acidic than the peptide bond amide. The gas-phase acidities for the model compounds acetamide $\left(\mathrm{CH}_{3} \mathrm{C}(=\mathrm{O}) \mathrm{NH}_{2}\right)$ and $\mathrm{N}$-methyl acetamide $\left(\mathrm{CH}_{3} \mathrm{C}(=\mathrm{O}) \mathrm{NHCH}_{3}\right)$ were found to be identical within 2 $\mathrm{kJ} / \mathrm{mol}$ (i.e. within experimental accuracy) [64]. It is thus conceivable that upon collisional activation, the side chain amide proton is able to migrate to the C-terminal carboxylate, as sketched in Scheme 1. The second step is then a nucleophilic attack of the deprotonated amide nitrogen on the peptide bond carbonyl carbon, which produces a tetrahedral intermediate (Scheme 1). This is followed by charge and proton transfer that leads to rearrangement, fragmentation and formation of the succinimide $b_{2}$-anion.

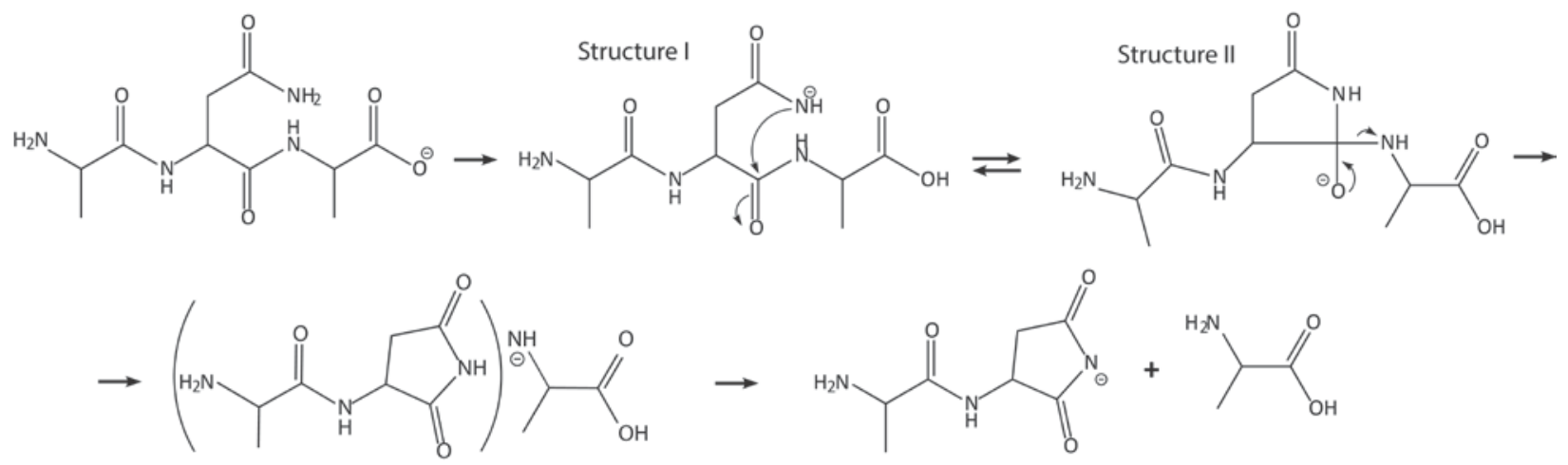

Scheme 1. Possible dissociation mechanism leading to a succinimide $b_{2}$-anion structure. The first step is proton transfer from the Asn side-chain nitrogen to the C-terminal carboxylate (structure I). The second step is a nucleophilic attack of the deprotonated amide nitrogen onto the peptide bond carbonyl carbon, which yields a tetrahedral intermediate (structure II), followed by proton transfer, generating the succinimide $b_{2}$-anion.

It is interesting to note that this mechanism is analogous to that described by the 'mobile proton' theory in the fragmentation of protonated peptides [65-67]. Although deprotonated species lack one proton instead of having one extra, Bache and coworkers showed that hydrogen scrambling occurs also in anionic peptides upon collisional excitation [68]. 


\section{$3.3 \mathrm{~b}_{3}$ anion from AlaAlaAsnAla}

Structures that we will consider as candidates for the $b_{3}$ fragment from deprotonated AANA are analogous to those considered for the $b_{2}$ fragments of ANA, with the exception that $a$ diketopiperazine structure cannot be formed for $a b_{3}$ anion. This structure is therefore excluded from the following discussion.

Upon irradiation with a $0.1 \mathrm{~s}$ long $\mathrm{CO}_{2}$ laser pulse, the main dissociation channels observed for deprotonated AANA (m/z 344) were loss of ammonia ( $\mathrm{m} / \mathrm{z} 327)$, the $b_{3}$ fragment $(\mathrm{m} / \mathrm{z} 255)$, the $c_{2}$ fragment $(m / z 158)$ and $m / z$ 96. Upon IRMPD of the isolated $b_{3}$ fragment, dissociation into the $c_{2}$-ion and $\mathrm{m} / \mathrm{z} 96$ was observed. This resembles the fragmentation pathway observed for the $b_{2}$ anion from ANA ( $c_{1}$ and $96 \mathrm{~m} / \mathrm{z}$ ), suggestive of similar fragment structures.

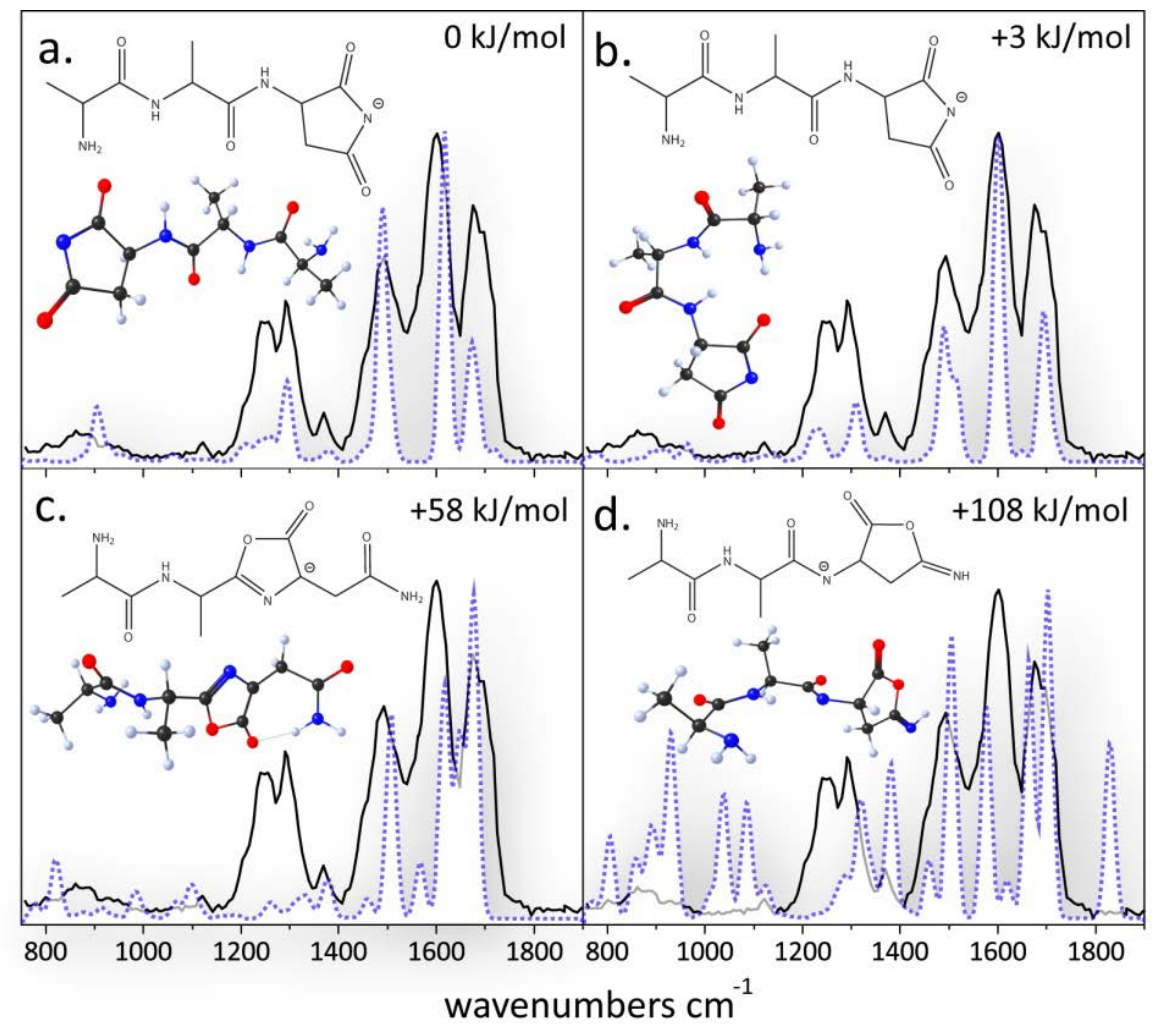

Figure 4. IRMPD spectrum of the $b_{3}$ ion of deprotonated AANA (black in all panels) compared to DFTcalculated spectra (blue dashed line) for candidate structures. Calculated relative free energies are given for each of the structures 
Figure 4 presents a direct comparison of the experimental IRMPD spectrum of the $b_{3}$-anion with computed IR spectra for various candidate structures: succinimide deprotonated at the succinimde nitrogen atom (Figure $4 \mathrm{a}$ and $4 \mathrm{~b}$ ), oxazolone deprotonated the $\alpha$-carbon atom in the oxazolone ring (Figure 4c) and imino- $\gamma$-butyrolactone deprotonated at the peptide bond nitrogen atom (Figure 4d). Relative free energy values are given for each of the structures. It is immediately obvious that good agreement between experiment and theory is only achieved for the succinimide structures in panels $\mathbf{a}$ and $\mathbf{b}$. These two conformations of the succinimide isomer also possess the lowest energies, while the computed energy difference between them is insignificantly small $(3 \mathrm{~kJ} / \mathrm{mol})$. In addition, the two conformers have nearly identical computed spectra. In the diagnostic $1500-1700 \mathrm{~cm}^{-1}$ region, it appears that the best match is provided by conformer b. However, based on experimental and calculated spectra, it cannot be excluded that a mixture of these conformers is present, which is not unlikely on the basis of their similar stabilities.

According to the calculated vibrational frequencies and normal modes, the most intense bands in the experimental spectrum at 1675, 1601 and $1493 \mathrm{~cm}^{-1}$ originate from peptide bond carbonyl stretching, asymmetric succinimide carbonyl stretching and NH bending modes, respectively. The next band of interest lies at $1296 \mathrm{~cm}^{-1}$ and is due to the succinimide NC stretching vibration. The broader and relatively intense band at about $1240 \mathrm{~cm}^{-1}$ is due to two unresolved vibrational bands, which are identified as succinimide $\mathrm{C}-\mathrm{H}$ rocking and $\mathrm{N}-\mathrm{H}$ wagging. Less intense bands between $900-1200 \mathrm{~cm}^{-1}$ show reasonable overlap with the computed spectra and are a result of different $\mathrm{C}-\mathrm{H}$ and $\mathrm{N}-\mathrm{H}$ coupled vibrations.

Figure 5 shows an overlay of the experimental spectra of $b_{2}$ from ANA and $b_{3}$ from AANA. Consistency of the most intense bands in these two spectra clearly suggests a large extent of similarity between the isomeric structures of the $b_{2}$ - and $b_{3}$-fragments. Slight offsets between the bands is due to the additional amide moiety in the $b_{3}$ ion as compared to $b_{2}$, the higher level of conformational freedom of the $b_{3}$ anion as well as the possibility to establish additional hydrogen bonds, which result in shifts of particular absorptions of the groups involved. 


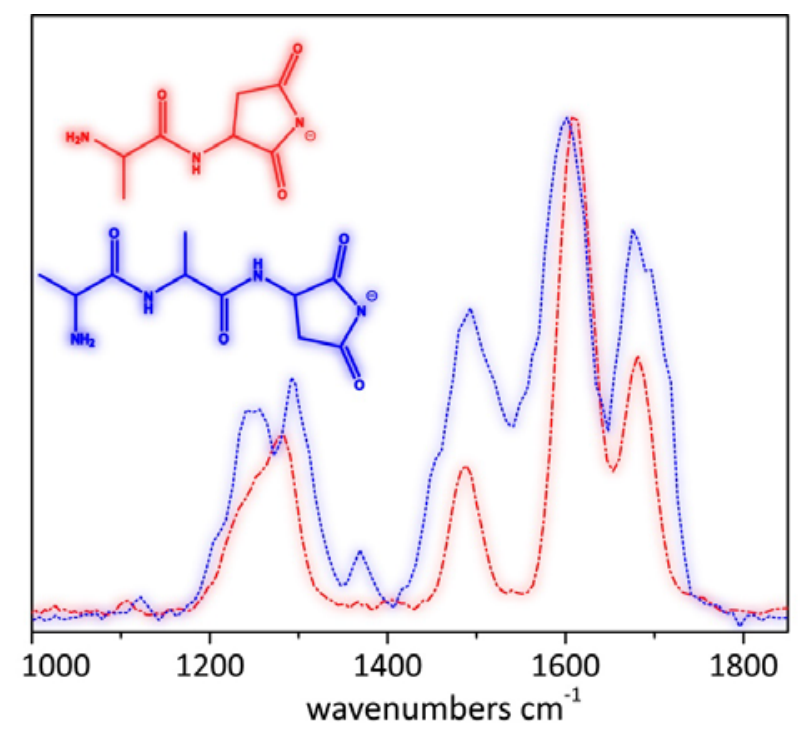

Figure 5. Overlaid IRMPD spectra of the $b_{3}$ (blue dotted line) from AANA and $b_{2}$ ion of deprotonated ANA (red dash-dot line). Consistency of the most intense bands of these two spectra suggests similarity of the corresponding fragment structures.

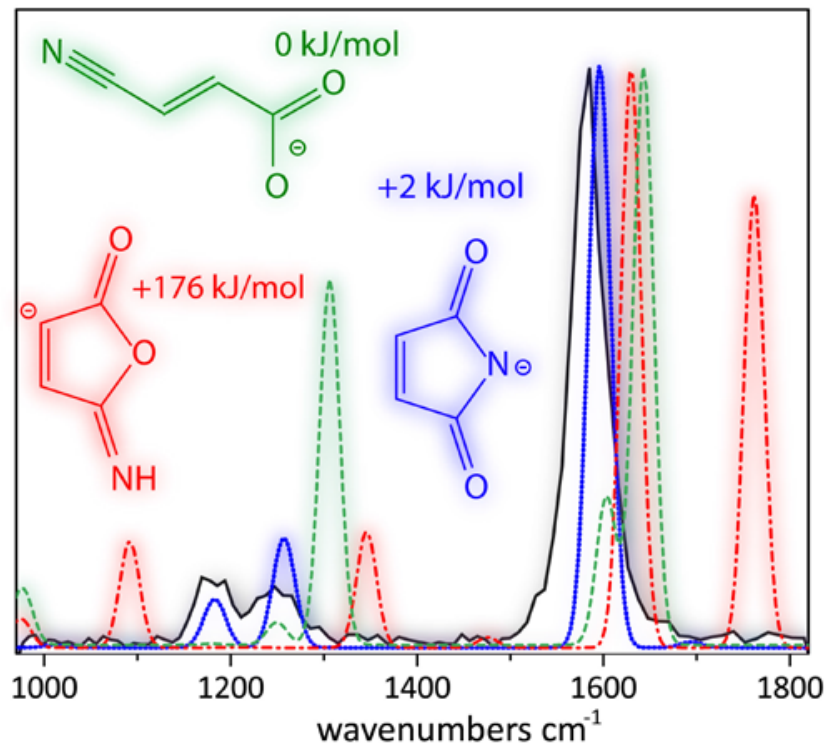

Figure 6. IRMPD spectrum of the $\mathrm{m} / \mathrm{z} 96$ anion of deprotonated AANA (black) compared to DFTcalculated IR spectra for candidate structures: maleimide deprotonated at the nitrogen atom (blue dotted), 5-imino-furan-2-one deprotonated at the carbon atom adjacent to the carbonyl group (red dot-dashed) and a possible linear carboxylate structure (green dashed). 


\subsection{Spectroscopic identification of the $\mathrm{m} / \mathrm{z} 96$ fragment}

Further experimental confirmation of our assignment as succinimide structures for $b_{2}$ and $b_{3}$ fragment anions can be obtained by establishing the structure of the $\mathrm{m} / \mathrm{z} 96$ fragment that they appear to have in common. To this end, the experimental spectrum of the $\mathrm{m} / \mathrm{z} 96 \mathrm{fragment}$ generated from the $b_{3}$ anion of deprotonated AANA was recorded and is presented in Figure 6. Isolation of the $\mathrm{m} / \mathrm{z} 96$ fragment and subsequent resonant IRMPD with FELIX generates a single fragment anion at $\mathrm{m} / \mathrm{z} 42$, corresponding to $\mathrm{NCO}^{-}$. The IRMPD spectrum was produced by plotting the wavelength-dependent yield of this fragment.

From the IRMPD spectrum recorded and its comparison to computed spectra, it is unambiguous that this ion is the maleimide (3,4-dehydrogenated succinimide) anion deprotonated at the nitrogen atom, and not the alternative 5-imino-furan-2-on anion that would have been expected from a $\gamma$-butyrolactone $b$-fragment structure. Isomeric structures for $\mathrm{m} / \mathrm{z} 96$, also including an alternative linear carboxylate structure, are presented in Figure 6 and their corresponding computed vibrational spectra are marked by color. Only three bands are observed in the experimental spectrum, positioned at 1185, 1247 and $1585 \mathrm{~cm}^{-1}$. We attribute them to vibrations of the maleimide anion as the $\mathrm{C}-\mathrm{N}-\mathrm{C}$ asymmetric stretching mode with some contribution from the $\mathrm{C}-\mathrm{H}$ rocking motion, the $\mathrm{C}-\mathrm{N}-\mathrm{C}$ symmetric stretching mode and the $\mathrm{C}=\mathrm{O}$ asymmetric stretching mode, respectively. A straightforward mechanism can be proposed to explain the formation of the $\mathrm{m} / \mathrm{z} 96$ fragment anion from the succinimide $b_{3}$ peptide fragment anion (see Scheme 2).

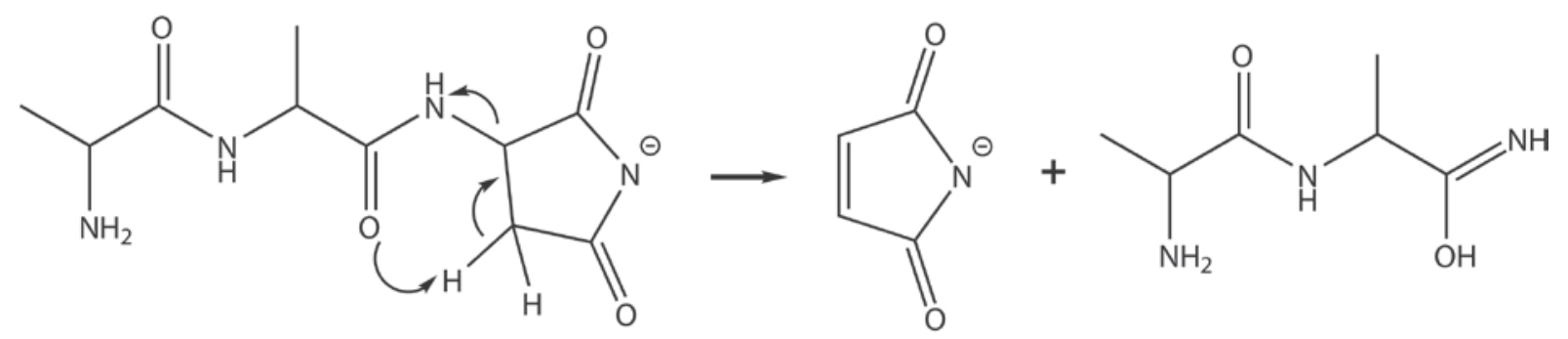

Scheme 2. Suggested fragmentation pathway leading to the formation of the maleimide anion from the $b_{3}$ fragment of deprotonated AANA. 


\section{Conclusion}

IRMPD spectroscopy using a free electron laser was applied to investigate the structures of short anionic $b$-type peptide fragments generated from peptides containing Asn, in particular from ANA and AANA. Comparison with calculated spectra show unambiguously that the $b_{2}$ fragment from ANA and the $b_{3}$ fragment from AANA do not possess the classical oxazolone structure, but instead adopt cyclic succinimide structures, deprotonated on the succinimide nitrogen. These findings are consistent with tandem MS data of the $b_{2}$ and $b_{3}$ fragments, i.e. with formation of $c_{1}$ (from $b_{2}$ ) and $c_{2}$ (from $b_{3}$ ) anions, as well as with maleimide formation at $\mathrm{m} / \mathrm{z} 96$ (from both $b_{2}$ and $b_{3}$ ).

The succinimide structures are likely formed via nucleophilic attack of the side chain amide nitrogen, which becomes deprotonated upon collsional activation and proton migration. For both peptide fragment anions, the thermochemically most favored fragment is formed. Deprotonation at the succinimide ring is favored over other deprotonation sites (amide proton of the peptide linkage in particular) since it provides delocalization of the negative charge over five atoms (succinimide nitrogen and two carbonyl groups), which results in enhanced gasphase stability. A detailed reaction pathway would require further computational investigation of the potential energy surfaces involved in the fragmentation reactions, which is beyond the scope of this study.

It is of interest to investigate fragment ion structures of deprotonated peptides containing other functionalized residues. In light of the present findings for Asn-containing peptides, the behavior of the glutamine $(G \mid n)$ residue is of particular interest as it also contains an amide moiety, though linked to the backbone by a longer alkyl chain. For protonated peptides containing Asn and Gln, similar involvement of the side-chain amide in the reactions forming $b$ ions was recently established using ion spectroscopy [42]. The role of Gln in the dissociation of deprotonated peptides is currently under study in our group. 


\section{Acknowledgments}

We gratefully thank the FELIX staff, in particular Drs. A.F.G. van der Meer, B. Redlich and G. Berden for their expert technical support. JO acknowledges the Stichting Physica for support. Financial support for this project has been provided by the Nederlandse Organisatie voor Wetenschappelijk Onderzoek (NWO) in the form of VICl grant no. 724.011.002. This work is part of the research program of FOM, which is financially supported by NWO

\section{References}

[1] R. Aebersold, D.R. Goodlett, Mass spectrometry in proteomics, Chem. Rev., 101 (2001) 269-295.

[2] H. Steen, M. Mann, The ABC's (and XYZ's) of peptide sequencing, Nat. Rev. Mol. Cell Biol., 5 (2004) 699-711.

[3] J.R. Yates, Mass spectrometry and the age of the proteome, J. Mass Spectrom., 33 (1998) 1-19.

[4] C.K. Barlow, R.A.J. O'Hair, Gas-Phase Peptide Fragmentation: How Understanding the Fundamentals Provides a Springboard to Develping New Chemistry and Novel Proteomics Tools, J. Mass Spectrom., 43 (2008) 1301.

[5] J.R. Eyler, Infrared multiple photon dissociation spectroscopy of ions in Penning traps, Mass Spectrom. Rev., 28 (2009) 448-467.

[6] N.C. Polfer, J. Oomens, Vibrational spectroscopy of bare and solvated ionic complexes of biological relevance, Mass Spectrom. Rev., 28 (2009) 468-494.

[7] N.C. Polfer, J. Oomens, Reaction products in mass spectrometry elucidated with infrared spectroscopy, Phys. Chem. Chem. Phys., 9 (2007) 3804-3817.

[8] N.C. Polfer, J. Oomens, S. Suhai, B. Paizs, Spectroscopic and theoretical evidence for oxazolone ring formation in collision-induced dissociation of peptides, J. Am. Chem. Soc., 127 (2005) 17154-17155.

[9] N.C. Polfer, J. Oomens, S. Suhai, B. Paizs, Infrared spectroscopy and theoretical studies on gas-phase protonated Leu-enkephalin and its fragments: Direct experimental evidence for the mobile proton, J. Am. Chem. Soc., 129 (2007) 5887-5897.

[10] P. Roepstorff, J. Fohlman, Proposal for a common nomenclature for sequence ions in mass spectra of peptides, Biomed. Mass Spectrom., 11 (1984) 601.

[11] J. Oomens, S. Young, S. Molesworth, M. van Stipdonk, Spectroscopic evidence for an oxazolone structure of the $b_{2}$ fragment ion from protonated tri-alanine, J. Am. Soc. Mass Spectrom., 20 (2009) 334339.

[12] S.H. Yoon, J. Chamot-Rooke, B.R. Perkins, A.E. Hilderbrand, J.C. Poutsma, V.H. Wysocki, IRMPD spectroscopy shows that AGG forms an oxazolone $b_{2}{ }^{+}$ion, J. Am. Chem. Soc., 130 (2008) 17644-17645.

[13] B.R. Perkins, J. Chamot-Rooke, S.H. Yoon, A.C. Gucinski, A. Somogyi, V.H. Wysocki, Evidence of diketopiperazine and oxazolone structures for $\mathrm{HA} \mathrm{b}_{2}{ }^{+}$ion, J. Am. Chem. Soc., 131 (2009) 17528-17529.

[14] A.G. Harisson, Peptide Sequence Scrambling Through Cyclization of b5 Ions, J. Am. Soc. Mass Spectrom., 19 (2008) 1776-1780. 
[15] C. Bleiholder, S. Osburn, T.D. Williams, S. Suhai, M. Van Stipdonk, A.G. Harrison, B. Paizs, Sequencescrambling fragmentation pathways of protonated peptides, J. Am. Chem. Soc., 130 (2008) 1777417789.

[16] S. Molesworth, C.M. Leavitt, G.S. Groenewold, J. Oomens, J.D. Steill, M. Van Stipdonk, Spectroscopic evidence for mobilization of amide position protons during CID of model peptide ions, J. Am. Soc. Mass Spectrom., 20 (2009) 1841-1845.

[17] X. Chen, J.D. Steill, J. Oomens, N.C. Polfer, Oxazolone versus macrocycle structures for LeuEnkephalin $b_{2}-b_{4}$ : Insights from infrared multiple-photon dissociation spectroscopy and gas-phase hydrogen/deuterium exchange, J. Am. Soc. Mass Spectrom., 21 (2010) 1313-1321.

[18] U. Erlekam, B.J. Bythell, D. Scuderi, M. Van Stipdonk, B. Paizs, P. Maitre, Infrared spectroscopy of fragments of protonated peptides: Direct evidence for macrocyclic structures of $b_{5}$ ions, J. Am. Chem. Soc., 131 (2009) 11503-11508.

[19] U.H. Verkerk, C.K. Siu, J.D. Steill, H. El Aribi, J. Zhao, C.F. Rodriguez, J. Oomens, A.C. Hopkinson, K.W.M. Siu, $a_{2}$ Ion Derived from Triglycine: $A_{n} N_{1}$-Protonated 4-Imidazolidinone, J. Phys. Chem. Lett., 1 (2010) 868-872.

[20] B.J. Bythell, P. Maitre, B. Paizs, Cyclization and Rearrangement Reactions of $a_{n}$ Fragment lons of Protonated Peptides, J. Am. Chem. Soc., 132 (2010) 14766-14779.

[21] H.J. Andreazza, T. Wang, D. Bilusich, P. Hoffmann, J.H. Bowie, Negative ion fragmentations of deprotonated peptides containing post-translational modifications: diphosphorylated systems containing Ser, Thr and Tyr. A characteristic phosphate/phosphate cyclisation. A joint experimental and theoretical study, Rapid Commun. Mass Spectrom., 23 (2009) 1825-1833.

[22] C.S. Brinkworth, S. Dua, A.M. McAnoy, J.H. Bowie, Negative ion fragmentations of deprotonated peptides: backbone cleavages directed through both Asp and Glu, Rapid Commun. Mass Spectrom., 15 (2001) 1965-1973.

[23] J.H. Bowie, C.S. Brinkworth, S. Dua, Collision-induced fragmentations of the (M-H)- parent anions of underivatized peptides: An aid to structure determination and some unusual negative ion cleavages, Mass Spectrom. Rev., 21 (2002) 87-107.

[24] D. Pu, N.L. Clipston, C.J. Cassady, A comparison of positive and negative ion collision-induced dissociation for model heptapeptides with one basic residue, J. Mass Spectrom., 45 (2010) 297-305.

[25] H. Song, K. Håkansson, Electron detachment dissociation and negative ion infrared multiphoton dissociation of electrosprayed intact proteins, Anal. Chem., 84 (2011) 871-876.

[26] A. Harrison, Effect of phenylalanine on the fragmentation of deprotonated peptides, J. Am. Soc. Mass. Spectrom., 13 (2002) 1242-1249.

[27] A.G. Harrison, A.B. Young, Fragmentation reactions of deprotonated peptides containing aspartic acid, Int. J. Mass Spectrom., 255-256 (2006) 111-122.

[28] A.G. Harrison, Sequence-specific fragmentation of deprotonated peptides containing $\mathrm{H}$ or alkyl side chains J. Am. Soc. Mass Spectrom., 12 (2001) 1-13.

[29] Z. Li, T. Yalcin, C.J. Cassady, C-terminal amino acid residue loss for deprotonated peptide ions containing glutamic acid, aspartic acid, or serine residues at the C-terminus, J. Mass Spectrom., 41 (2006) 939-949.

[30] L. Men, Y. Wang, Fragmentation of the deprotonated ions of peptides containing cysteine, cysteine sulfinic acid, cysteine sulfonic acid, aspartic acid, and glutamic acid, Rapid Commun. Mass Spectrom., 20 (2006) 777-784.

[31] D. Pu, C.J. Cassady, Negative ion dissociation of peptides containing hydroxyl side chains, Rapid Commun. Mass Spectrom., 22 (2008) 91-100.

[32] R.J. Waugh, J.H. Bowie, R.N. Hayes, Collision induced dissociations of deprotonated peptides: Dipeptides containing phenylalanine, tyrosine, histidine and tryptophan, Int. J. Mass Spectrom., 107 (1991) 333-347. 
[33] A.G. Harrison, K.W.M. Siu, H. El Aribi, Amide bond cleavage in deprotonated tripeptides: a newly discovered pathway to " $b_{2}$ ions, Rapid Comm. Mass Spectrom., 17 (2003) 869-875.

[34] R.J. Waugh, J.H. Bowie, M.L. Gross, Collision-Induced Dissociations of Deprotonated Peptides. Dipeptides Containing Asn, Arg and Lys, Australian Journal of Chemistry, 46 (1993) 693-702.

[35] J. Oomens, J.D. Steill, The structure of deprotonated tri-alanine and its $a_{3}$ fragment anion by IR spectroscopy, J. Am. Soc. Mass Spectrom., 21 (2010) 698-706.

[36] J. Grzetic, J. Oomens, Spectroscopic evidence for an oxazolone structure in anionic b-type peptide fragments, J. Am. Soc. Mass Spectrom., 23 (2012) 290-300.

[37] J. Grzetic, J. Oomens, Structure of anionic c-type peptide fragments elucidated by IRMPD spectroscopy, Int. J. Mass Spectrom., 316-318 (2012) 216-226.

[38] J.M. Farrugia, R.A.J. O'Hair, G.E. Reid, Do all $b_{2}$ ions have oxazolone structures? Multistage mass spectrometry and ab initio studies on protonated $\mathrm{N}$-acyl amino acid methyl ester model systems, Int. J. Mass Spectrom., 210-211 (2001) 71-87.

[39] A.G. Harrison, Fragmentation reactions of protonated peptides containing glutamine or glutamic acid, J. Mass Spectrom., 38 (2003) 174-187.

[40] Y.J. Lee, Y.M. Lee, Formation of $c 1$ fragment ions in collision-induced dissociation of glutaminecontaining peptide ions: a tip for de novo sequencing, Rapid Comm. Mass Spectrom., 18 (2004) 20692076.

[41] D. Winter, J. Seidler, B. Hahn, W. Lehmann, Structural and mechanistic information on $c_{1}$ ion formation in collision-induced fragmentation of peptides, J. Am. Soc. Mass Spectrom., 21 (2010) 18141820.

[42] J. Grzetic, J. Oomens, Spectroscopic identification of cyclic imide $b_{2}$-ions from peptides containing Gln and Asn residues, J. Am. Soc. Mass Spectrom., in press (2013).

[43] N.E. Robinson, A.B. Robinson, Molecular Clocks: Deamidation of Asparaginyl and Glutaminyl Residues in Peptides and Proteins, (2004).

[44] E.B. Dunkelberger, L.E. Buchanan, P. Marek, P. Cao, D.P. Raleigh, M.T. Zanni, Deamidation Accelerates Amyloid Formation and Alters Amylin Fiber Structure, Journal of the American Chemical Society, 134 (2012) 12658-12667.

[45] J.J. Valle, J.R. Eyler, J. Oomens, D.T. Moore, A.F.G. van der Meer, G. von Helden, G. Meijer, C.L. Hendrickson, A.G. Marshall, G.T. Blakney, Free electron laser-Fourier transform ion cyclotron resonance mass spectrometry facility for obtaining infrared multiphoton dissociation spectra of gaseous ions, Rev. Sci. Instrum., 76 (2005) 023103.

[46] D. Oepts, A.F.G. van der Meer, P.W. van Amersfoort, The infrared free-electron laser facility FELIX, Infrared Phys. Technol., 36 (1995) 297.

[47] A.G. Marshall, T.C.L. Wang, T.L. Ricca, Tailored excitation for Fourier transform ion cyclotron mass spectrometry, J. Am. Chem. Soc., 107 (1985) 7893-7897.

[48] C.J. Shaffer, A. Revesz, D. Schröder, L. Severa, L. Teply, E.-L. Zins, L. Jasikova, J. Roithova, Can Hindered Intramolecular Vibrational Energy Redistribution Lead to Non-Ergodic Behavior of MediumSized Ion Pairs?, Angew. Chem. Int. Ed., 51 (2012) 10050-10053.

[49] T.H. Mize, I. Taban, M. Duursma, M. Seynen, M. Konijnenburg, A. Vijftigschild, C.V. Doornik, G.V. Rooij, R.M.A. Heeren, A modular data and control system to improve sensitivity, selectivity, speed of analysis, ease of use, and transient duration in an external source FTICR-MS, Int. J. Mass Spectrom., 235 (2004) 243-253.

[50] G.W.T. M. J. Frisch, H. B. Schlegel, G. E. Scuseria, M. A. Robb, J. R. Cheeseman, G. Scalmani, V. Barone, B. Mennucci, G. A. Petersson, H. Nakatsuji, M. Caricato, X. Li, H. P. Hratchian, A. F. Izmaylov, J. Bloino, G. Zheng, J. L. Sonnenberg, M. Hada, M. Ehara, K. Toyota, R. Fukuda, J. Hasegawa, M. Ishida, T. Nakajima, Y. Honda, O. Kitao, H. Nakai, T. Vreven, J. A. Montgomery, Jr., J. E. Peralta, F. Ogliaro, M. Bearpark, J. J. Heyd, E. Brothers, K. N. Kudin, V. N. Staroverov, R. Kobayashi, J. Normand, K. 
Raghavachari, A. Rendell, J. C. Burant, S. S. Iyengar, J. Tomasi, M. Cossi, N. Rega, J. M. Millam, M. Klene, J. E. Knox, J. B. Cross, V. Bakken, C. Adamo, J. Jaramillo, R. Gomperts, R. E. Stratmann, O. Yazyev, A. J. Austin, R. Cammi, C. Pomelli, J. W. Ochterski, R. L. Martin, K. Morokuma, V. G. Zakrzewski, G. A. Voth, P. Salvador, J. J. Dannenberg, S. Dapprich, A. D. Daniels, Ö. Farkas, J. B. Foresman, J. V. Ortiz, J. Cioslowski, and D. J. Fox, Gaussian, Inc., Wallingford CT, , Gaussian 09, Revision A.1, (2009).

[51] G.N. Merrill, S.R. Kass, Calculated Gas-Phase Acidities Using Density Functional Theory: Is It Reliable?, J. Phys. Chem., 100 (1996) 17465-17471.

[52] J. Oomens, J.D. Steill, Free carboxylate stretching modes, J. Phys. Chem. A, 112 (2008) 3281-3283.

[53] W. Kulik, W. Heerma, Fast Atom Bombardment Tandem-Mass Spectrometry for Amino-Acid Sequence Determination in Tripeptides, Biomed. Environ. Mass Spectrom., 18 (1989) 910-917.

[54] R.J. Waugh, J.H. Bowie, A review of the collision induced dissociations of deprotonated dipeptides and tripeptides. An aid to structure determination., Rapid Commun. Mass Spectrom., 8 (1994) 169-173.

[55] J.H. Bowie, C.S. Brinkworth, S. Dua, Collision-induced fragmentations of the (M - H)- parent anions of underivatized peptides: an aid to structure determination and some unusual negative ion cleavages Mass Spectrom. Rev., 21 (2002) 87-107.

[56] M. Eckersley, J.H. Bowie, R.N. Hayes, Collision-Induced Dissociations of Deprotonated Peptides, Dipeptides and Tripeptides with Hydrogen and Alkyl Alpha-Groups - An Aid to Structure Determination, Org. Mass Spectrom., 24 (1989) 597-602.

[57] A. Harrison, A. Young, Fragmentation of deprotonated N-benzoylpeptides: Formation of deprotonated oxazolones, J. Am. Soc. Mass. Spectrom., 15 (2004) 446-456.

[58] P.A. Wabnitz, R.J. Waugh, M.A. Eckersley, S. Dua, T. Blumenthal, J.H. Bowie, The negative ion mass spectra of deprotonated 2,5-diketopiperazines, Int. J. Mass Spectrom. Ion Processes, 154 (1996) 193201.

[59] W.E. Sinclair, D.W. Pratt, Structure and vibrational dynamics of aniline and aniline-Ar from high resolution electronic spectroscopy in the gas phase, J. Chem. Phys., 105 (1996) 7942-7956.

[60] H. Piest, G. von Helden, G. Meijer, Infrared spectroscopy of jet-cooled neutral and ionized anilineAr, J. Chem. Phys., 110 (1999.) 2010-2015.

[61] S. Capasso, L. Mazzarella, F. Sica, A. Zagari, S. Salvadori, Kinetics and mechanism of succinimide ring formation in the deamidation process of asparagine residues, J. Chem. Soc., Perkin Trans. 2, (1993) 679682.

[62] R.A.J. O'Hair, J.H. Bowie, S. Gronert, Gas phase acidities of the alpha amino acids, Int. J. Mass Spectrom. Ion Proc., 117 (1992) 23-36.

[63] C.M. Jones, M. Bernier, E. Carson, K.E. Colyer, R. Metz, A. Pawlow, E.D. Wischow, I. Webb, E.J. Andriole, J.C. Poutsma, Gas-phase acidities of the 20 protein amino acids Int. J. Mass Spectrom., 267 (2007) 54-62.

[64] M. Decouzon, O. Exner, J.-F. Gal, P.-C. Maria, The Gas-Phase Acidity and the Acidic Site of Acetohydroxamic Acid: A FT-ICR Study, J. Org. Chem., 55 (1990) 3980-3981.

[65] O. Burlet, R.S. Orkiszewski, K.D. Ballard, S. Gaskell, Charge promotion of low-energy fragmentations of peptide ions, Rapid Commun. Mass Spectrom., 6 (1992) 658-662.

[66] V.H. Wysocki, G. Tsaprailis, L.L. Smith, L.A. Breci, Mobile and localized protons: a framework for understanding peptide dissociation, Journal of Mass Spectrometry, 35 (2000) 1399-1406.

[67] R. Boyd, A. Somogyi, The mobile proton hypothesis in fragmentation of protonated peptides: a perspective, J. Am. Soc. Mass Spectrom., 21 (2010) 1275-1278.

[68] N. Bache, K.D. Rand, P. Roepstorff, M. Ploug, T.J.D. Jørgensen, Hydrogen Atom Scrambling in Selectively Labeled Anionic Peptides Upon Collisional Activation by MALDI Tandem Time-of-Flight Mass Spectrometry, J. Am. Soc. Mass. Spectrom., 19 (2008) 1719-1725. 